\title{
IMPLEMENTASI NILAI PANCASILA SEBAGAI TINJAUAN ATAS MENTALITAS ANAK BANGSA INDONESIA
}

\author{
Fajriyatur Robi'ah \& Dinie Anggraeni Dewi \\ Universitas Pendidikan Indonesia \\ fajriyatur@gmail.com
}

\begin{abstract}
Abstrak
Penelitian ini dilakukan bertujuan untuk mengetahui dan menganalisis lebih dalam mentalitas bangsa Indonesia khususnya dalam diri anak muda bangsa Indonesia. Kajian penelitian ini menggunakan metode kualitatif atau pendekatan secara deskriptif dimana teori ataupun dasar pembahasannya diperoleh dari hasil studi kepustakaan dengan berbagai sumber seperti buku, jurnal dan artikel. Metode ini digunakan untuk mencari kebenaran dalam suatu fakta yang terjadi dan berfokus kepada pemahaman fenomena sosial yang terjadi di masyarakat. Dalam penelitian ini, dapat diketahui bahwa moral dan mentalitas anak bangsa dapat menjadi cerminan masa depan bangsa. Dengan adanya revolusi mental guna memperbaiki mentalitas anak bangsa dapat menciptakan sumber daya manusia yang berkualitas. Maka pentingnya penerapan nilai-nilai Pancasila dalam berperilaku guna menciptakan individu yang bermoral. Dengan mengkiblatkan perilaku kepada nilai-nilai Pancasila diharapkan dapat menjadi awal kemajuan bangsa Indonesia. Dan dibuatnya artikel ini sebagai langkah awal dalam membuka perhatian mengenai pentingnya memperbaiki mentalitas anak bangsa.
\end{abstract}

Kata Kunci: Pancasila, mentalitas, moral

\begin{abstract}
This research was conducted to determine and analyze more deeply the mentality of the Indonesian nation, especially in the Indonesian youth. This research study uses a qualitative method or a descriptive approach where the theory or basis of discussion is obtained from the results of literature studies with various sources such as books, journals and articles. This method is used to find the truth in a fact that occurs and focuses on understanding social phenomena that occur in society. In this research, it can be seen that the morality and mentality of the nation's children can be a reflection of the nation's future. With the mental revolution in order to improve the mentality of the nation's children, it can create quality human resources. So the importance of implementing Pancasila values in behavior in order to create moral individuals. By cultivating behavior to the values of Pancasila, it is hoped that it can be the beginning of the progress of the Indonesian nation. And this article was made as a first step in opening attention to the importance of improving the mentality of the nation's children.
\end{abstract}

Keywords: Pancasila, mentality, morals

\section{PENDAHULUAN}

Moral dan mental anak muda zaman sekarang semakin merosot dan kehilangan arah. Anak muda seperti tidak bisa mengontrol dirinya dalam bersikap dan berperilaku. Hancurnya mentalitas anak bangsa Indonesia dapat menuntun bangsa Indonesia kedalam jurang kehancuran karena moral dan mental merupakan aspek penting dalam terciptanya sumber daya manusia yang berkualitas. Hal itu menunjukan bahwa Indonesia sudah harus melakukan tindakan korektif dengan mempropagandakan revolusi mental yang sesuai dengan budaya nusantara yang bersahaja dan berkesinambungan (Kristiawan, M. 2016).

Mental berperan dalam kehidupan seseorang dan pergaulan hidupnya, ada orang-orang yang siap dalam menghadapi kenyataan hidup dan ada juga orang-orang yang tidak siap dalam menghadapi kenyataan hidup (Sibaweh, I. 2015). Jika anak muda memiliki mental yang lemah maka akan berpengaruh dalam menentukan pergaulan hidupnya. Hal itu 
lah yang menyebabkan hancurnya moral anak muda zaman sekarang dengan memilih pergaulan yang salah. Pergaulan itulah yang akhirnya menciptakan perilaku-perilaku amoral yang ditunjukkan oleh anak muda zaman sekarang (Dewantara \& Nurgiansah, 2021).

Perilaku amoral dapat dilihat dari perilaku anak muda zaman sekarang seperti meningkatnya perilaku merusak diri seperti penggunaan narkoba, alkohol, dan seks bebas. Kondisi tersebut berdampak kepada kemajuan bangsa. Remaja yang merupakan generasi penerus tidak dapat diharapkan untuk aset yang dibanggakan (Prasasti, S. 2017). Tak hanya itu, perilaku amoral lain dapat terlihat dari semakin kaburnya moral baik dan buruk. Permasalahan-permasalahan tersebut mengharuskan kita melindungi dan menyelamatkan bangsa dari kehancuran (Dewantara, Nurgiansah, et al., 2021).

Sebagai salah satu cara memperbaiki moral anak muda zaman sekarang, diperlukannya revolusi mental guna memperbaiki mentalitas yang tak terkendali. Dengan mengkiblatkan perilaku kepada nilai-nilai Pancasila dapat menjadi solusi dalam membentuk karakteristik yang baik dalam diri anak bangsa. Dengan adanya revolusi mental diharapkan adanya perubahan mendasar dalam mentalitas, cara berpikir, cara merasa dan cara mempercayai yang menjelma dalam perilaku dan tindakan keseharian (Desmita, D. 2016).

\section{METODE PENELITIAN}

Penelitian ini menggunakan pendekatan kualititatif atau pendekatan deskriptif dengan metode studi litelatur. Peneliti mencari sumber teori dan dasar pembahasannya dengan menganalisis dari berbagai sumber literatur yang nantinya dijadikan sebuah kesimpulan. Sumber penelitiannya diperoleh dari hasil studi kepustakaan dari berbagai referensi seperti buku, artikel, dan jurnal dengan mengkaji dan menganalisis lebih dalam menggunakan data atau teori yang dianalisis secara deskriptif. Kesimpulan diambil dengan mengolah data yang selanjutnya dianalaisis dengan tersusun dan terperinci. Peneliti berperan sebagai human instrument dimana dapat menetapkan fokus dari penelitian dan mencari sumber informasi yang kemudian dianalisis dan ditafsirkan serta dibuat kesimpulannya. Sumber teori yang dijadikan landasan harus berkesinambungan dengan penelitian implementasi nilai Pancasila sebagai tinjauan mentalitas anak bangsa Indonesia.

\section{HASIL PENELITIAN DAN PEMBAHASAN Hasil Penelitian}

Manusia melakukan berbagai upaya untuk meningkatkan kehidupan yang lebih baik melalui pengembangan ilmu pengetahuan dan teknologi. Namun, kehidupan semakin mengalami kemunduran dan keterpurukan. Hal ini disebabkan oleh realitas dimana kehidupan saat ini telah jauh dari nilai-nilai keberadaban. Negeri ini dianggap telah kehilangan identitas diri karena telah memudarnya nilai-nilai kesejatian diri sebagai bangsa yang terhormat dan bermartabat akibat merebaknya tindakan amoral yang terus mematahkan sendisendi kehidupan berbangsa dan bernegara (Nurgiansah, 2021a).

Nilai-nilai keberadaban telah terkikis oleh perilaku biadab yang melewati batas kesakralan nilai Pancasila. Hal ini mencerminkan tidak adanya karakter yang kuat untuk menciptakan bangsa yang berperadaban maju. Dunia ini seakan-akan sudah dipenuhi oleh manusia yang lumpuh kepekaan nurani, moral dan religinya. Kondisi itu tentunya tidak sebanding dengan tujuan dilaksanakannya pendidikan nasional. Seperti dalam UU No. 22 Tahun 2003 Pasal 3 tentang Sistem 
Pendidikan Nasional yang berbunyi "Pendidikan nasional berfungsi mengembangkan kemampuan dan membentuk watak serta peradaban bangsa yang bermartabat dalam rangka mencerdaskan kehidupan bangsa bertujuan untuk berkembangnya potensi peserta didik agar menjadi manusia beriman dan bertakwa kepada Tuhan yang Maha Esa, berakhlak mulia, sehat, berilmu, cakap, kreatif, mandiri, dan menjadi warga negara yang demokratis serta bertanggung jawab.

Menurut Akbar (2011) dalam (Herlambang, Y. T. 2018) bahwa terdapat 10 ciri manusia Indonesia yang 9 diantaranya menunjukan sikap negatif bangsa Indonesia dan hanya satu ciri yang menunjukkan sikap positif bangsa Indonesia. Ciri-ciri manusia Indonesia tersebut adalah ramah, malas, tidak disiplin, korup, emosional, individualis, suka meniru, rendah diri, boros, dan percaya takhayul. Ciri-ciri tersebut telah merekat erat pada masyarakat Indonesia dan mungkin saja melekat pada diri kita sendiri. Hal tersebut sangatlah miris, seakan bangsa Indonesia sedang menghadapi lonceng kematian (Dewantara, Hermawan, et al., 2021).

Berdasarkan ciri diatas, hal ini merupakan gambaran mentalitas buruk bangsa Indonesia. Hal tersebut dapat disebabkan oleh beberapa faktor diantaranya:

1. Reformasi Bangsa yang Kebablasan

2. Masyarakat yang Kehilangan Jati Diri

3. Kehilangan Kesabaran dan Kearifan

4. Masyarakat Tak Berintegritas dan Kontra Produktif

5. Masyarakat Indonesia Masih Suka Membenarkan Kebiasaan daripada Membiasakan Kebenaran

6. Masyarakat Indonesia Rendah dalam Berpikir

\section{Pembahasan}

Menurut Putri, A. L., Charista, F. D. F., Lestari, S., \& Trisiana, A. (2020), pendidikan merupakan salah satu aspek terpenting dalam membangun negara. Dalam mengembangkan pendidikan perlu diterapkan nilai-nilai Pancasila agar pendidikan dapat menciptakan sumber daya manusia yang berkualitas yang menjunjung tinggi nilai-nilai Pancasila. Dengan memiliki sumber daya manusia yang berkualitas, Indonesia dapat berkembang jauh lebih cepat dan menjadi bangsa yang bermutu.

Dalam Darmadi, H. (2020) menyatakan bahwa pemerintah menilai sosialisasi Pancasila paling efektif adalah dengan memasukkannya kedalam kurikulum pendidikan. Adapun mata pelajaran yang dianggap berkaitan dengan Pancasila yaitu Pendidikan Agama, Pendidikan Kewarganegaraan, Pendidikan Bahasa Indonesia, Pendidikan Bahasa Daerah, dan Pendidikan Olahraga. Dengan dimasukannya Pancasila dalam ranah pendidikan diharapkan dapat menjadi pendidikan karakter yang secara tidak langsung menjadi tolak ukur anak dalam berperilaku.

Fauzi, F. Y., Arianto, I., \& Solihatin, E. (2013) mengatakan bahwa pendidikan memiliki peranan penting dalam membentuk karakter. Dalam dunia pendidikan, terdapat sejumlah mata pelajaran yang dapat membentuk karakter bangsa, salah satu diantaranya adalah mata pelajaran PPKn. Mata pelajaran PPKn membahas mengenai nilai-nilai Pancasila sebagai pembentuk kepribadian. Hal itu tentunya sesuai dengan tujuan pendidikan yaitu untuk membentuk kepribadian yang berakhlak mulia sesuai dengan nilai-nilai Pancasila.

Dari ketiga pernyataan diatas dapat diketahui bahwa pendidikan sangat diperlukan dalam membentuk pribadi yang berkualitas. Pribadi yang berkualitas tersebut dapat dilihat melalui perilaku dan 
perbuatannya dalam kehidupan seharihari. Perilaku yang mencerminkan nilainilai Pancasila merupakan perilaku yang terpuji karena nilai-nilai Pancasila itu sendiri merupakan aturan dalam berperilaku agar sesuai dengan norma yang ada. Oleh sebab itu, implementasi nila- nilai Pancasila diperlukan dalam memperbaiki mentalitas bangsa Indonesia khususnya anak muda yang menjadi masa depan bangsa (Nurgiansah, 2021b).

Berkaitan dengan hal diatas, pembentukan kualitas bangsa Indonesia tidaklah sempurna jika tidak dibekali dengan karakter yang kuat agar dapat menjadi bangsa yang berkehidupan maju. Permasalahan-permasalahan yang ada tidak dapat membuat kita hanya diam dan menunggu takdir kehancuran tiba. Kita perlu berpikir untuk mencari solusi atas keterpurukan ini dengan melahirkan strategi dan upaya untuk membangun mentalitas bangsa Indonesia yang kuat dan berkarakter.

Perlu adanya patokan untuk menjadikan Indonesia sebagai negara yang bermartabat. Dengan adanya upaya mengontruksi mentalitas bangsa Indonesia yang kuat dan berkarakter melalui reorientasi pendidikan yang berlandaskan nilai-nilai Pancasila dapat menjadi sebuah upaya di tengah permasalahan yang ada (Nurgiansah, 2021c). Orientasi pendidikan tersebut berdasarkan realitas pendidikan yang ada saat ini. Saat ini pendidikan hanya ditujukan untuk mencapai kecerdasan intelektual, akal, dan penalaran tanpa diimbangi dengan kecerdasan hati nurani, emosi, dan spiritual yang sebenarnya menjadi hal yang utama dalam diri manusia.

Dalam upaya membangun kembali mentalitas bangsa Indonesia dibutuhkan upaya yang secara kritis difokuskan pada pengembangan manusia yang berkualitas tinggi. Manusia berkualitas tinggi yaitu yang senantiasa menjunjung tinggi nilai- nilai keberadaban yang dibangun berdasarkan norma-norma agama dan sosial yang ada. Salah satu upaya dalam merekontruksi mentalitas bangsa Indosenia dapat dengan merevitalisasikan pendidikan secara teoretis maupun praktis yang direkontruksi berdasarkan landasan filosofis Pancasila (Nurgiansah, 2021d).

Manusia membutuhkan rancangan hidup untuk menjadi acuan dalam menata kehidupan pribadi maupun sosial. Banyaknya permasalahan di Indonesia menunjukkan bahwa nilai Pancasila tidak dilakukan dengan semestinya. Nilai Pancasila telah tergerus dalam kehidupan bermasyarakat, berbangsa dan bernegara (Budimansyah, D. 2020). Jadi, Pancasila sebagai acuan dalam menata kehidupan perlu diterapkan kembali dalam kehidupan bermasyarakat, berbangsa, dan bernegara.

Dengan mengimplementasikan nilainilai Pancasila dalam kehidupan seharihari maka akan terciptanya karakter yang kuat dan bermartabat. Implementasi nilainilai Pancasila di era globalisasi bagi peserta didik bisa dilakukan dengan menumbuhkan sifat nasionalisme pada peserta didik (Asmaroini, A. P. 2016). Nilainilai Pancasila pun dapat diterapkan melalui mata pembelejaran dalam jenjang pendidikan SD, SMP maupun SMA.

Menurut Efendi, Y., \& Sa'diyah, $\mathrm{H}$. (2020) melalui pembelajaran kewarganegaraan di tingkat dasar diharapkan peserta didik memiliki potensi jati diri bangsa Indonesia sehingga perilaku dan moral anak bangsa dapat mewujudkan cita-cita bangsa Indonesia yaitu menjadi manusia pancasilais.

Dalam mengontruksi mentalitas bangsa Indonesia pun tak hanya pendidikan formal yang dibutuhkan namun praktik akan pendidikan yang didapatkan disekolah juga harus terimplementasikan dalam kehidupan sehari-hari. Adapun nilai praksis sila-sila Pancasila yang dapat diimplementasikan dalam kehidupan 
sehari-hari dalam (Kardiman, Y. dkk. 2018) yaitu.

1. Ketuhanan Yang Maha Esa

a. Menghormati dan bekerja sama antarumat beragama sehingga tercipta kerukunan berbangsa dan bernegara

b. Menghormati kebebasan beribadah agama lain

2. Kemanusiaan yang adil dan beradab

a. Pengakuan persamaan derajat, hak dan kewajiban antarwarga negara

b. Menumbuhkan rasa cinta dan tenggang rasa antarwarga negara

c. Menghargai dan menjunjung nilai kemanusiaan

d. Membela kebenaran dan keadilan

3. Persatuan Indonesia

a. Menempatkan persatuan, kesatuan, kepentingan dan keselamatan bangsa dan negara di atas kepentingan pribadi atau golongan

b. Menumbuhkan kerelaan berkorban untuk kepentingan bangsa dan negara

c. Bangga sebagai bangsa Indonesia dan bertanah air Indonesia, seperti bangga memakai produk-produk Indonesia

4. Kerakyatan yang dipimpin oleh hikmat kebijaksanaan dalam permusyawaratan perwakilan

a. Mengedepankan musyawarah ketika mengambil keputusan untuk kepentingan bersama

b. Berani dan siap mempertanggung jawabkan setiap keputusan musyawarah secara moral kepada Tuhan Yang Maha esa

5. Keadilan sosial bagi seluruh bangsa Indonesia

a. Ikut serta membantu orang-orang yang membutuhkan, seperti pendidikan

b. Hidup hemat

c. Menghargai karya orang lain
Menurut Larasati, H. R., \& Supratman, Y. B. (2021) nilai-nilai Pancasila perlu dipertahankan karena Pancasila merupakan karakter dan budaya bangsa Indonesia. Pancasila juga merupakan sebuah ciri khas bangsa Indonesia yang menjadi sebuah pembeda dengan bangsa lain. Pancasila dapat dijadikan sebagai karakter bangsa dengan menanamkan nilainilai Pancasila dalam diri bangsa Indonesia. Pendidikan karakter tak hanya melibatkan pengetahuan namun juga melibatkan perilaku yang baik (Nurgiansah, 2020).

Tak hanya peserta didik, pendidik pun perlu memiliki karakteristik pancasilais dalam dirinya sehingga diperlukan pemahaman terhadap nilainilai Pancasila oleh pendidik. Selaras dengan pernyataan (Sasmito, Y. A., \& Fathoni, A. 2019) yaitu untuk mengembangkan prinsip Pancasila melalui pendidikan, guru perlu memahami makna prinsip Pancasila dan mengembangkannya dalam kegiatan pembelajaran.

\section{KESIMPULAN}

Dari hasil penelitian yang telah dilakukan, dapat disimpulkan bahwa semakin hari, mentalitas bangsa Indonesia semakin menunjukkan keterpurukannya. Norma-norma agama dan sosial nampaknya tidak cukup kuat untuk dijadikan sebuah batasan dalam berperilaku dalam kehidupan sehari-hari. Dibutuhkannya solusi guna memperbaiki mentalitas bangsa Indonesia untuk menciptakan sumber daya manusia yang berkualitas dan membawa bangsa Indonesia kepada kemajuan.

Permasalahan hancurnya moral dan mentalitas bangsa Indonesia mencerminkan pudarnya nilai-nilai Pancasila sebagai acuan dalam berperilaku. Oleh karena itu, nilai-nilai Pancasila perlu dibangkitkan kembali dan ditumbuhkan kembali dalam diri manusia Indonesia. Nilai-nilai Pancasila dapat ditanamkan 
dalam pendidikan formal sebagai revitalisasi pendidikan guna memperbaiki moral bangsa Indonesia.

Tak hanya dalam dunia pendidikan, nilai-nilai Pancasila pun perlu ditanamkan dalam kehidupan bermasyarakat, berbangsa dan bernegara. Implementasi nilai-nilai Pancasila perlu diperkuat dan ditumbuhkan kembali kesadaran akan berperilaku sehingga segala perilaku dalam kehidupan sosial bertumpu pada nilai-nilai Pancasila.

Dari uraian diatas maka peneliti memberikan saran sebagai berikut: Sekolah perlu lebih menekankan pendidikan karakter yang sesuai nilai-nilai Pancasila kepada peserta didik, pemerintah perlu mengoptimalkan perannya dalam bertindak tegas mengatasi perilaku amoral yang terjadi di masyarakat, pemerintah perlu mengadakan pendidikan Pancasila sebagai solusi dari permasalahan moral yang membengkak, adanya pemahaman yang diajarkan sejak dini oleh orang tua mengenai mental danmoral.

\section{DAFTAR PUSTAKA}

Asmaroini, A. P. (2016). Implementasi Nilai-Nilai Pancasila Bagi Siswa Di Era Globalisasi. Citizenship Jurnal Pancasila dan Kewarganegaraan, 4(2), 440-450.

Budimansyah, D. (2020). MKU Pendidikan Pncasila. YouTube: Prof. Budimansyah

Darmadi, H. (2020). APA MENGAPA BAGAIMANA PEMBELAJARAN PENDIDIKAN MORAL PANCASILA DAN PENDIDIKAN PANCASILA DAN KEWARGANEGARAAN (PPKn): konsep dasar strategi memahami ideologi pancasila dan karakter bangsa. An1mage.

Desmita, D. (2016). Revolusi Mental Dan Revolusi Etos Kerja: Upaya Membangun Bangsa Indonesia Yang Lebih Bermartabat. Ta'dib, 18(1), 1-12.

Dewantara, J. A., Hermawan, Y., Yunus, D., Prasetiyo, W. H., Efriani, Arifiyanti, F., \& Nurgiansah, T. H. (2021). Anti-Corruption Education as an Effort to Form Students With Character Humanist and Law-Compliant. Jurnal Civics: Media Kajian Kewarganegaraan, 18(1), 7081.

Dewantara, J. A., \& Nurgiansah, T. H. (2021). Building Tolerance Attitudes Of PPKN Students Through Multicultural Education Courses. Jurnal Etika Demokrasi, 6(1), 103-115.

Dewantara, J. A., Nurgiansah, T. H., \& Rachman, F. (2021). Mengatasi Pelanggaran Hak Asasi Manusia dengan Model Sekolah Ramah HAM (SR-HAM). Edukatif: Jurnal Ilmu Pendidikan, $3(2), 261-269$.

Efendi, Y., \& Sa'diyah, H. (2020). Penerapan Nilai-Nilai Pancasila Dalam Lembaga Pendidikan. JPK (Jurnal Pancasila dan Kewarganegaraan), 5(1), 54-65.

Fauzi, F. Y., Arianto, I., \& Solihatin, E. (2013). Peran guru Pendidikan Pancasila dan Kewarganegaraan dalam upaya pembentukan karakter peserta didik. Jurnal PPKn UNJ Online, 1(2), 1-15.

Herlambang, Y. T. (2018). Pedagogik: Telaah Kritis Ilmu Pendidikan Dalam Multiperspektif. Bandung: Bumi Aksara.

Kardiman, Y. dkk. (2018). Pendidikan Pancasila dan Kewarganegaraan. Jakarta: Erlangga.

Kristiawan, M. (2016). Telaah Revolusi Mental dan Pendidikan Karakter dalam Pembentukkan Sumber Daya Manusia Indonesia Yang Pandai dan Berakhlak Mulia. Ta'dib, 18(1), 13-25.

Larasati, H. R., \& Supratman, Y. B. (2021). Hubungan Mata Pelajaran Pancasila Di Sekolah Terhadap Penerapan Implementasi Pancasila Pada Pelajar. Jurnal Pancasila dan Bela Negara, 1(1).

Nurgiansah, T. H. (2020). Filsafat Pendidikan. In Banyumas: CV Pena Persada.

Nurgiansah, T. H. (2021a). Pendidikan Pancasila. In Solok: CV Mitra Cendekia Media. 
Nurgiansah, T. H. (2021b). Pendidikan Pancasila Sebagai Upaya Membentuk Karakter Jujur. Jurnal Pendidikan Kewarganegaraan Undiksha, 9(1), 33-41.

Nurgiansah, T. H. (2021c). Petuah Pendidikan Kewarganegaraan Dalam Kontestasi Politik. AoEJ: Academy of Education Journal, 12(1), 39-47.

Nurgiansah, T. H. (2021d). The Role of Citizenship Education in Building Bantul Community Political Participation in The Pandemic Covid 19. Prosiding Seminar Nasional Pendidikan Dan Kewirausahaan, 4(1), 1-4.

Prasasti, S. (2017, July). Kenakalan remaja dan faktor penyebabnya. In Prosiding Seminar Nasional Bimbingan dan Konseling (Vol. 1, No. 1, pp. 28-45).

Putri, A. L., Charista, F. D. F., Lestari, S., \& Trisiana, A. (2020). Implementasi Pancasila Dalam Pembangunan Dibidang Pendidikan. TERAMPIL: Jurnal Pendidikan dan Pembelajaran Dasar, 7(1), 13-22.

Sasmito, Y. A., \& Fathoni, A. (2019). Implementasi Nilai-Nilai Pancasila Untuk Menumbuhkan Rasa Nasionalisme di SDN 03 Ngemplak (Doctoral dissertation, Universitas Muhammadiyah Surakarta).

Sibaweh, I. (2015). Pendidikan Mental Menuju Karakter Bangsa:: Berdasarkan Ilmu Pengetahuan Dari Masa Ke Masa. Deepublish. 